\title{
Hypertension and Dyslipidemia among Type II Diabetic Patients and Related Risk Factors and Complications
}

\author{
Eman H. Waly and Mona S. Hamed
}

Public Health and Community Medicine Department, Faculty of Medicine, Zagazig University, Egypt

Received :January $2017 \quad$ Accepted : March 2017

\begin{abstract}
Background:Diabetics are likely to develop hypertension. Hypertension occurs in about $70 \%$ of type II diabetics moreover, it clusters with other cardiovascular risk factors such as obesity, insulin resistance and dyslipidemia.Objective:To estimate the prevalence of hypertension and dyslipidemia amongtype II diabetic patients and to identify common risk factors and complications of type II diabetes with hypertension.Methods:A Cross sectional study was conducted on type II diabetics attending outpatient clinics at Zagazig University and El-Ahrar Hospitals.Participants were selected by systematic random sampling. Data were collected about participants' socio-demographic characteristics, life style risk factors, andexistent diabetic complications.Blood pressure, Body Mass Index,serum fasting glucose, total cholesterol, and triglyceride levels were measured.Results:Prevalence of hypertension, hypercholesterolemia and hypertriglyceridemia were $68 \%, 57.3 \%$, and $47 \%$ respectively. Hypertension significantly occurred among female, elderly,and low social patientsand associated with family history of DM, physical inactivity or not following diabetic diet. Diabetic hypertensive patients were significantly obese and havinghigh cholesterol and fasting blood sugar (FBS). They were significantly complicated with FBS >300 mg/dl, ocular and cardiovascular diseases.Conclusion:There was increased prevalence of hypertension and dyslipidemia among type II diabetics. Hypertension was common in low social old aged obese diabetic patients not following diabetic diet and regular exercise and those with high cholesterol and fasting blood sugar. Hypertensive diabetics were prone to many complications as hyperglycemia, ocular problems and CVD.Recommendations:Further studies are needed to explore related risk factors of hypertension and dyslipidemia among type II diabetics, Health education programs are recommended for both clinicians and diabetic patients for early detection and management of hypertension and dyslipidemia.
\end{abstract}

Key words:Hypertension, Dyslipidemia, Prevalence, Type II diabetes, Risk factors, Complications.

Corresponding author:Eman Hasan Waly E-mail: eman_waly78@yahoo.com

\section{Introduction}

Recently, diabetes and other noncommunicable diseases that share similar risk factors represent a prominent threat to human health and development. Every year in developing countries about 8 to 14 million person are exposed to premature death as a cause of preventable non communicable diseases mainly cardiovascular diseases CVD, diabetes, and chronic respiratory diseases ${ }^{1}$. 
Diabetes is recognized as a group of heterogeneous disorders with the common elements of hyperglycemia and glucose intolerance, due to insulin deficiency, impaired effectiveness of insulin action or both $^{2}$. The number of people with diabetes is increasing all over the world as a cause of several factors as population growth, aging, physical inactivity, and obesity ${ }^{3}$.

The global prevalence of diabetes among adults (aged 20-79 years) is 6.4\%, affecting 285 million adults, in 2010, and will increase to $7.7 \%$ and 439 million adults by $2030^{4}$. In Egypt The prevalence percentage adjusted to world population in 2010 is 11.4 and will be 13.7 in 2030, number of adults with diabetes in 2010 is 4.787 million and will be 8.6 million in $2030^{4}$.The International Diabetes Federation (IDF) has recognized Egypt as the ninth leading country in the world for the number of type II diabetes patients and its prevalence was nearly tripled over the last 2 decades 5 .

There isa close relationship between diabetes and hypertension that has been recognized since the $1980 \mathrm{~s}^{6}$. Diabetics are likely to develop hypertension ${ }^{7}$. Approximately, $85 \%-95 \%$ of diabetics suffer from type II diabetes. Among Type I diabetic patients, hypertension occurs in only $30 \%$ of cases, while $70 \%$ of patients with type II diabetes have hypertension ${ }^{8,9}$. Commonly, hypertension in type II diabetic persons clusters with some risk factors such as central obesity, insulin resistance, dyslipidemia, hyper-coagulation and left ventricular hypertrophy ${ }^{10}$. This clustering result in the development of several complications especially CVD, which is the major cause of premature mortality in type II diabetic patients ${ }^{10,11}$.Among middle aged and elderly Egyptians it was identified that, there is a high prevalence of metabolic syndrome in $55 \%$ among all of them, $76.6 \%$ among hypertensive patients and $85.6 \%$ among diabetics ${ }^{12}$.

Diabetes mellitus is now the fourth or fifth leading cause of death in most highincome countries and there is considerable evidence that it is epidemic in many economically developing and newly industrialized nations ${ }^{3}$. Hypertension is twice as common in people with diabetes as in those without ${ }^{13}$ while it is under diagnosed and undertreated among diabetics ${ }^{9}$. Hypertension doubles the risk of cardiovascular events ${ }^{8}$. Therefore, the aim of this study is to estimate the prevalence of hypertension and dyslipidemia amongpatients with type II diabetes mellitus in Zagazig district hospitals, and to study some common risk factors and complications of type II diabetes with hypertension.

\section{Methods:}

Study design and setting: A Cross sectional study was carried out on type II diabetic patients attending diabetic outpatient clinics at ZagazigUniversity and El-Ahrar Hospitals for a period of three months from 1st June to the end of August 2015.Diabetic Outpatient Clinic at Zagazig university hospital and El-Ahrar Hospital were chosen to conduct this study as they act as a first health care contact serving Zagazig city population and adjacent rural areas, they service about 2000 patients per month, and they are sites for giving free medication to diabetic patients so the drop out of patients was expected to be minimal.

Study Population and Sampling: The target population included type II diabetic patient attending diabetic outpatient clinic at Zagazig university hospital and El-Ahrar Hospital. Assuming that the prevalence of hypertriglyceridemia among Type 
IIdiabetic patients was $(25.5 \%)^{14}$ with total population (outpatient clinics attendants) was 2000, the estimated sample size was 252 plus $20 \%$ non-response. So the total sample size was 300 participants calculated by Epi- info program version 6 with a confidence interval $95 \%$ and $80 \%$ as the power of test. Our participants were selected by the systematic random sampling technique.Listing of the patients was done two days per week then every 3rd patient coming to the clinic in those days and fulfilling the inclusion criteria was chosen after a random starting point.

Inclusion criteria: Not hospitalized apparently uncomplicated type II diabetic patients above 40 years old (the peak age of type 2 diabetes incidence ${ }^{15}$ who attended diabetic outpatient clinic and fasting from 12-14 hours for taking a blood sample for laboratory investigation.

Exclusion criteria: Not hospitalized complicated type II diabetic patients <40 years old and smoker patients.

Data collection:A]A structured questionnaire was used to collect data regarding the participants' sociodemographic as: age, sex, social class (social class was classified as low class $<50 \%$, moderate class $\geq 50-75 \%$, high class $\geq 75 \%)^{16}$ andfamily history of DM among first degree relatives and some life style risk factors as: regular physical activity (it is defined as 30 minutes or more a day 3 times/week or daily physical activity lasting at least $20 \mathrm{~min}$ daily or 1 hour of physical activity twice a week $)^{17}$, and following the diabetic dietas well as the presence of otherdiabetes complications.B]Clinical

examination:Blood pressure has been measured once in sitting position following the standard precaution ${ }^{18}$ and patient was considered hypertensive when systolic blood pressure was more than $140 \mathrm{mmHg}$ and diastolic blood pressure was more than $90 \mathrm{mmHg}^{19}$. Body Mass Index BMI of participants was calculated (considering < 18 is under weight, from 18 to $\leq 25$ is normal weight, from 25 to $\leq 30$ is overweight, and > 30 is obese $)^{20} . \mathbf{C}$ ]Laboratory investigations:One blood sample $(3 \mathrm{ml})$ was obtained from each participant included in the study. Serum fasting glucose, serum total cholesterol, and fasting plasma triglyceride were determined using the enzymatic method. DM type II patient defined as the person who has symptoms of diabetes and or fasting blood glucose of $>126$ $\mathrm{mg} / \mathrm{dl}^{21}$. Cholesterol level $<200 \mathrm{mg} / \mathrm{dl}$ was considered normal, $200-250 \mathrm{mg} / \mathrm{dl}$ was borderline high and $>250 \mathrm{mg} / \mathrm{dl}$ was high and Triglyceride level $<150 \mathrm{mg} / \mathrm{dl}$ were defined as normal, $150-200 \mathrm{mg} / \mathrm{dl}$ as borderline high and $>200 \mathrm{mg} / \mathrm{dl}$ as high risk. Dyslipidemia was defined as the presence of one or more of the previous abnormalities in serum lipids or patient receiving medications for this condition ${ }^{22}$. Metabolic syndrome was defined as having central obesity (BMI is $>30 \mathrm{~kg} / \mathrm{m}^{2}$ ) plus any two of the following four factors: elevated triglycerides $\geq 150 \mathrm{mg} / \mathrm{dl}$, reduced HDL (good) cholesterol in men $<40 \mathrm{mg} / \mathrm{dl}$ and in women $<50 \mathrm{mg} / \mathrm{dl}$, elevated blood pressure $\geq 130 / 85 \mathrm{mmHg}$, and elevated fasting glucose $\geq 100 \mathrm{mg} / \mathrm{dl}^{23}$.

Ethical considerationand administrative approach: The necessary official permission was taken from the manager of diabetic outpatient clinics at Zagazig University and El-Ahrar Hospitals. An informed consent was obtained from the participants and they were reassured about the confidentiality of information and the results were used for the purpose of the scientific research and they were also given the right to refuse or participate in the study. 
Pilot study: A pilot study was carried out before starting data collection which involved 30 selected type II diabetic patients who were not included in the study to test the clarity and applicability of the questionnaire and necessary modifications were made accordingly.

Statistical Analysis: Statistical analysis was conducted using SPSS software version 19.0. Qualitative data were represented in tables and figures as frequencies and relative percentages. Chi square and t-tests were used to calculate significant differences between hypertensive and non-hypertensive type II diabtic patients.

\section{Results}

Figure (1) shows that, the prevalence of hypertension was $68 \%$ among the studied type II diabetic patients. $57.3 \%$ of the studied patients had high cholesterol level and $47 \%$ of them had high triglyceride level. The criteria of metabolic syndrome had been fulfilled in $84 \%$ of the studied patients.

Table (1) reveals that, hypertension was significantly occurred in female and older aged diabetic patients. Low social class, positive family history of DM, and regular physical exercise were significantly associated with hypertensive diabetic patients. Also, there were significant differences regarding following diabetic diet between both hypertensive and nonhypertensive diabetic patients in favour to non-hypertensive ones.

Table (2) shows that, both Systolic and Diastolic Blood Pressures were significantly higher among the hypertensive diabetic patients. Hypertension with diabetes was significantly associated with obesity, border high and high cholesterol and high fasting blood sugar levels.
Table (3) illustrates that, diabetic hypertensive patients were statistically significantly more likely to have FBS above $300 \mathrm{mg} / \mathrm{dl}$ and complaining of eye problems and cardiovascular diseases CVD than Diabetic non hypertensive ones.

\section{Discussion}

The relation between type II diabetes and essential hypertension has the potential to provide insight into the mechanisms that operate this complex interaction ${ }^{24}$.The current study aimed to estimate the prevalence of hypertension and dyslipidemia amongpatients with type II diabetes mellitus in Zagazig district hospitals, and to study some common risk factors and complications of type II diabetes with hypertension.

There is considerable evidence for an increased prevalence of hypertension in diabetic persons and in the USA population; hypertension occurs in about $50 \%$ to $80 \%$ of type II diabetes patients ${ }^{25}$.Also, in the current study the prevalence of hypertension was $68 \%$ among the studied type II diabetic patients (Figure 1).This finding was consistent with other previous studies ${ }^{26,27}$, while higher in percentage than a study among type II diabetic patients in Kuwait ${ }^{14}$ which concluded that hypertension was present in only $56 \%$ of their patients. Also diabetic hypertensive patients showed higher levels of SBP, DBP than diabetic non hypertensive ones with statistical significance difference $(\mathrm{p}<0.001)$ (table 2$)$. The present study showed high prevalence of dyslipidemia among the studied diabetic patients (Figure 1) which was in agreement with two previous studies ${ }^{27,28}$ the former one showed lower percentage of total cholesterol and slightly higher triglyceride levels (46\% and $49 \%$ ) respectively, while a study in Kuwait ${ }^{14}$ reportedthat $67 \%$ of their 
diabetic patients had high total cholesterol and $25 \%$ of them had high triglycerides. The pathophysiology of dyslipidemia in type II DM is complex and multifactorial ${ }^{29}$. Studies have shown that improved glycemic control can lead to promising changes in HDL-cholesterol and triglyceride levels ${ }^{30}$.It was revealed that $84 \%$ of the studied type II diabetic patients have metabolic syndrome (Figure 1) which was much higher than a pervious study ${ }^{28}$ revealed that $31.7 \%$ of studied Saudi type II diabetic patients had metabolic syndrome. This can be explained by higher prevalence of obesity, uncontrolled FBS and higher prevalence of hypertension among the studied sample which fulfill the inclusion criteria of metabolic syndrome. The present study showed that the mean ages of both hypertensive and nonhypertensive diabetic groups were $(56.58 \pm$ $6.74)$ and (52.02 \pm 7.69) respectively (Table1), which was very near to the results found by previous studies ${ }^{26,27}$. The risk of hypertension had been significantly increased when diabetic patients became older $^{31}$. Numerous epidemiological studies showed that the frequency of hypertension is higher among elderly population ${ }^{32,33,34}$. An epidemiological study revealed that, incidence of hypertension is more than doubled in the aged than in the young population $^{35}$. In agreement with the previous studies we found that hypertension was significantly occurred older aged diabetic patients (Table 1).

Hypertension incidence was increased in women higher than in men especially after the fifth decade of life ${ }^{36}$ and several survey studies showed the diabetic female predominance ${ }^{14,27,37}$.Hypertension had a significant tendency to affect female diabetic patients more than males ${ }^{38}$. These results were consistent with our results revealing that the diabetes was more predominant among females and the hypertension was significantly higher among female diabetic patients than male ones (Table 1). The impact of gender on the incidence of hypertension remains poorly clarified ${ }^{39}$.Possible explanations for diminished hypertension control in older women compared to older men include poorer adherence to prescribed medications or lifestyle recommendations and physiological differences because of vascular stiffness and/or sex hormones ${ }^{40}$.

Regarding the social class, the majority of the studied diabetic patients were of low social class with significant association with hypertension (Table 1). This finding was consistent with the results of a cross sectional study revealing that the prevalence of both hypertension and diabetes was significantly increased among low social classes in rural area ${ }^{41}$. A conducted in Pakistan ${ }^{27}$ revealed that, the majority of their survey study wasof low social class. However, other study revealed that high social classes had greater prevalence of hypertension and diabetes ${ }^{42}$.

The association between family history of diabetes and its occurrence has been well recognized $^{43}$. Recent studies have shown the graded contribution of a positive family history to escalating risk for diabetes $^{44,45}$. The inherited nature of hypertension is well recognized by numerous studies ${ }^{46}$, indicating association of hypertension withpositive family history $^{(47)}$. The prevalence of diabetes in newly diagnosed hypertensive patients was significantly higher in those with a family history in siblings ${ }^{48}$. This is in agreement with our finding revealed that, the positive family history of diabetes was significantly associated with hypertension (Table 1). Therefore, positive family history can be considered as a great chance for concerning direct family members and 
siblings in health education interventions for diabetes and hypertension.

Accomplishing recommended levels of physical exercise is a public health priority, and essential line measure in managing of type IIdiabetes and hypertension ${ }^{49,50}$. There was a great association between physical activity and improvement of both hypertension and diabetes $^{51}$ and it is considered a nonpharmacological intervention in controlling diabetes and reducing blood pressure $^{49,50}$. Also,six years follow up study on type II diabetic patients revealed that, regular physical exercise with following diabetic diet is strongly associated with normalizing glucose tolerance and controlling blood pressure, hyperlipidemia and hyperinsulinemia ${ }^{52}$. In agreement with the previous findings we found that, there was a significant association between nonfollowing regular physical activity and diabetic diet and occurrence of hypertension in the studied diabetic patients (Table 1).

USA has a high prevalence of obesity and overweight among the diabetic population $^{53}$. Also, an Egyptian study showed that, only $88.3 \%$ of Egyptian diabetics are overweight and obese which have a negative prognosis on their condition. Improvement in glucose tolerance in type II diabetic patients was correlated to weight reduction $(\mathrm{r}=0.19$, $\mathrm{p}<0.02)^{52}$. The incidence of hypertension in type II diabetic patients is related to the degree of obesity ${ }^{53}$. In accordance with the previous findings our results revealed that, obesity was significantly higher among the hypertensive diabetic group than the nonhypertensive one (Table 2).

The findings of our study shown that, hypertension was significantly associated with hypercholesterolemia $(\mathrm{P}<0.05)$ (Table 2). Several studies have consistently indicated frequent coexistence of hypertension and hypercholesterolemia;resultingin what is termed as dyslipidemic hypertension (DH) and its prevalence in the United States among elderly diabetic patients was $31 \%{ }^{54,55}$. Also, the co-occurrence of dyslipidemic hypertension has been named as "Lipitension" ${ }^{19}$.Highfasting blood glucose is associated with a higher prevalence of hypertension independent of other cardiovascular risk factors ${ }^{6}$.High fasting plasma sugar levels were significantly associated with of hypertension in both genders, with ORs of 1.24 (95 \% CI, 0.85-1.80) $\mathrm{p}<0.05$ in malepatients and 1.61 (95\% CI, 1.12$2.30) \mathrm{p}<0.01$ in female patients respectively ${ }^{6}$. The previous result is in agreement of ours which revealed that, fasting blood glucose was significantly higher among hypertensive diabetic patients than non- hypertensive $(\mathrm{P}=0.01)$ (Table 2).

Regarding the incidence of complications among the hypertensive and nonhypertensive diabetic patients our study illustrated that, FBS above $300 \mathrm{mg} / \mathrm{dl}$ and eye problems and cardiovascular diseases CVDwere significantly higher among hypertensive diabetic patients (Table 3). These results were consistent with several studies; In a Japanese cohort study after adjustment of age and gender an elevated concentration of fasting blood glucose was associated with hypertension $(\mathrm{OR}=1.35)$ during a 5-year follow-up ${ }^{56}$ and a study among Southern European found that,subjects with high FBS had more than two times the risk for association with hypertension than those with normal $\mathrm{FBS}^{57}$.The incidence of diabetic retinopathy is related primarily to duration and control of diabetes and is significantly related to hypertension ${ }^{58}$. The co- 
occurrence of dyslipidemic hypertension condition has proved to have adverse outcomes as interaction between hypertension and dyslipidemia occurs at the vascular endothelial level which results in augmented oxidative stress, endothelial dysfunction, and development of atherosclerosis and ends with a severeCVD ${ }^{59}$. The risk of CVD associated with coexistent hypertension and dyslipidemia is considered more multiplicative than the individual risk factors which emphasizing the need to quantify a person's overall CVD risk ${ }^{60}$. Strict control of hypertension has been recommended to be beneficial in controlling diabetic complications ${ }^{61}$.

\section{Conclusion and Recommendations}

There was considerable evidence for an increased prevalence of hypertension and dyslipidemia among studied type II diabetic patients. Hypertension was significantly occurred in female, older aged, low social class diabetic persons and also with those with positive family history of DM, and following regular physical exercise. Hypertension was significantly associated with not following diabetic diet, obesity, border high and high cholesterol and high fasting blood sugar levels. Finally, hypertensive diabetic patients were significantly prone to many complications ashyperglycemia, ocular problems, and CVD.

It is recommended that, the material discussed here regarding high prevalence of hypertension and dyslipidemia among type II diabetic patients and related complications help to proactively screen individuals who may benefit from further investigations or management, and refer complicated cases for specialized care. Further studies are needed to explore related risk factors of hypertension and dyslipidemia among type II diabetic patients, Health education programs are recommended for clinicians, type IIdiabetic patients and their family members to increase their awareness for early detection and management of both hypertension and dyslipidemia. The management of these disorders, especially in diabetic patients, requires multiple dietary and pharmacological interventions.

\section{References}

1. International Diabetes Federation (2009): Diabetes Atlas, 4th Ed. Brussels, International Diabetes Federation, 2009. Pr evalence.http://www.eatlas.idf.org/indexcc 67.html, ISBN: 9789241599979 (NLM classification: QT 255), ISBN-10: 0131995286 | ISBN-13: 978-0131995284.

2. Kumar P and Clark M (2009): Kumar \& Clark's. Clinical Medicine. 7 TH Ed., Sydney Toronto .2009. ISBN 9780702029936, International ISBN 9780702029929.

3. American Diabetes Association (2005): "Total Prevalence of Diabetes \& Prediabetes". Retrieved on 2006-03-17.

4. Shaw J, Sicree R and Zimmet P (2010): Global estimates of the prevalence of diabetes for 2010 and 2030. IDI Heart and Diabetes Institute, Australia Accepted 12 October 2009, diabetes research and clinical practice.(8):74-14.

5. Hegazi R, El-Gamal M, Abdel-Hady N, and Hamdy O (2015): Epidemiology of and Risk Factors for Type 2 Diabetes in Egypt. Ann Glob Health. 81(6):814-20.

6. Jamshed J,DalalTNC,Padmanabhan,Piyush Jain,Shiva Patil,HardikVasnawala, and AshishGulati (2012): LIPITENSION: Interplay between dyslipidemia and hypertension. Indian J EndocrinolMetab. 16(2): 240-245.

7. International Diabetes Federation (2006): Diabetes Atlas, third edition, IDF.2006. 
8. Macgregor G and Kaplan N (2006): fast facts: hypertension. 3rd ed. Oxford., UK: health press Ltd; 77.

9. Petri A, De lusignan S, Williams J, et al. (2006): Management of cardiovascular risk factors in people with diabetes in primary care: cross-sectional study.Public health.120: 654-663.

10. Sowers J, Epstein M and Frohlich E (2001): Diabetes, Hypertension, and Cardiovascular

Disease:Hypertension. 37:1053-

1059.Available online at:http://hyper.ahajo urnals .org /content/37/4/1053.full.pdf+html.

11. Govindarajan C, Sowers J and Stump C (2006): Hypertension and Diabetes Mellitus. European Cardiovascular Disease. 2006.

12. AbdElaziz KM, Gabal MS, Aldafrawy OA, AbouSeif HA, and Allam MF (2015): Prevalence of metabolic syndrome and cardiovascular risk factors among voluntary screened middle-aged and elderly Egyptians. J Public Health (Oxf). 37(4):612-7.

13. Williams B, Poulter N, Brown M, et al. (2004): The BHS Guidelines Working Party Guidelines for Management of Hypertension: Report of the Fourth Working Party of the British Hypertension Society.Journal of Human Hypertension; 1 8:139-185.

14. Al-Adsani A, Memon A and Suresh A (2004): Pattern and determinants of dyslipidaemia in type 2 diabetes mellitus patients in Kuwait, ActaDiabetol. 41:129 135.

15. Banegas JR, Lopez-Garcia E and Graciani A (2007): Relationship between obesity, hypertension and diabetes, and health-related quality of life among the elderly. Eur J Cardio vacPrevRehabil; 14(3):456-462.

16. Fahmy S and El-Sherbini AF (1983): Determining simple parameters for social classifications for health research. Bulletin of the High Institute of Public Health. 13:95-108.

17. World Health Organization (2010):Global recommendations on physical activity for health prevention and control, National health Programs, World Health Organization. Available online at; http://whqlibdoc.who.int/publications/2010 /9789241599979_eng.pdf.

18. Ibrahim MM et al., (2004): guidelines for management of hypertension In Egypt and developing countries, Egyptian Hypertension Society. February 2004, available on line at; www.ehs-egypt.net.

19. Chobanian AV, Bakris GL, Black HR et al. (2003): Seventh report of the Joint National Committee on prevention, detection, evaluation, and treatment of high blood pressure. Hypertension 2003;42(6):1206-52.

20. Bigal ME, Gironda M, Tepper SJ, et al., (2006): Headache prevention outcome and body mass index. Cephalalgia. 26(4):445-450. [PubMed]

21. American Diabetes Association (2008): Diagnosis and Classification of Diabetes Mellitus Diabetes Care vol. 31 no. Supplement 1 S55-S60.

22. American Diabetes Association (2004): Dyslipidemia management in adult with diabetes. Diabetes Care. 24:68-71.

23. International Diabetes Federation (2006): The IDF consensus worldwide definition of the metabolic syndrome. available at: http://www.idf.org/webdata/docs/IDF_Met a_def_final.pdf.

24. Weidmann P, de Courten $\mathrm{M}$, and Bohlen L (1993): Insulin resistance, hyperinsulinemia and hypertension. J Hypertens. 11 (suppl 5): S27-S38. 
25. Landsberg L andMolitch M (2004): Diabetes and hypertension: pathogenesis, prevention and treatment. ClinExpHypertens. 26:621-628.

26. Arafa NS and El Din GE (2010): The Epidemiology of Diabetes Mellitus in Egypt: Results of a National Survey The Egyptian Journal of Community Medicine. 28(3):29-43.

27. Shera AS, Jawad F, Maqsood A, Jamal S, Azfar M and Ahmed U (2004): Prevalence of Chronic Complications and Associated Factors in Type 2 Diabetes, JPMA. 54:54.

28. Aboserea MM (2009): Effect of Regular Physical Activity on Type 2 Diabetic Patients at Diabetic Center, $\mathrm{KFCH}$, Jazan, KSA, 2nd Diabetes Conference: Metabolic Syndrome. Held at Conference Hall, King Fahd Central Hospital, Jazan, KSA. 9-10.

29. World Health Organization (2006): Definition and diagnosis of diabetes mellitus and intermediate hyperglycemia: report of a WHO/IDF consultation, ISBN: 9241594934 (NLM classification: WK 810), ISBN: 978924159493.

30. Erdman DM, Cook CB, et al. (2002): The impact of outpatient diabetes management on serum lipids in urban African-Americans with type 2 diabetes.Diabetes Care. 25:9-15.

31. Addisu $Y$ Mengesha (2007):Hypertension and related risk factors in type 2 diabetes mellitus (DM) patients in Gaborone City Council (GCC) clinics, Gaborone, Botswana. Afr Health Sci. 7(4): 244-245. PMCID: PMC3074377.

32. Garcia-Palmieri

M(1995):

Hypertension in old age. P R Health Sci J.;14(3):217-21.

33. Lakatta EG (2013):Longitudinal trajectories of arterial stiffness and the role of blood pressure: the Baltimore
Longitudinal Study of Aging. Hypertension. 62:934-941.

34. Jiang L, Zhang J, Monticone RE, Telljohann R, Wu J, Wang M, Lakatta EG (2012):Calpain-1 regulation of matrix metalloproteinase 2 activity in vascular smooth muscle cells facilitates ageassociated aortic wall calcification and fibrosis. Hypertension.;60:1192-1199.

35. Ong KL, Cheung BM, Man YB, Lau CP, and Lam KS (2007):Prevalence, awareness, treatment, and control of hypertension among United States adults 1999-2004. Hypertension.;49:69-75.

36. Puntmann VO, Nagel E, Hughes AD, Gebker R, Gaddum N, Chowienczyk P, Jahnke C, Mirelis J, Schnackenburg B, Paetsch I, Fleck E (2012): Gender-specific differences in myocardial deformation and aortic stiffness at rest and dobutamine stress. Hypertension.59:712-718.

37. Chuengsamarn s, SutheeRattanamongkoulgul and Villarroel A (2010): Association between metabolic syndrome and risk of cardiovascular disease, using different criteria and stratified by sex. International Journal of Diabetes Mellitus.2(2):78-82.

38. Jane FReckelhoff (2001): Gender Differences in the Regulation of Blood Pressure. Hypertension.37:1199-1208. doi.org/10.1161/01.HYP.37.5.1199.

39. Doumas M, Papademetriou V, Faselis C, Kokkinos P (2013): Gender differences in hypertension: myths and reality.CurrHypertens Rep.;15(4):321-30. 40. Coylewright M, Reckelhoff JF, Ouyang P (2008): Menopause and Hypertension: An Age-Old Debate. Hypertension. 51(4):952-959.

41. Singh RB, Bajaj S, Niaz MA, Rastogi SS, Moshiri M (1998):Prevalence of type 2 diabetes mellitus and risk of hypertension and coronary artery disease in rural and urban population with low rates of 
obesity.Int J Cardiol. 1998 Sep 1;66(1):6572 .

42. Singh RB, Beegom R, Mehta AS, et al, (1998): Prevalence and risk factors of hypertension and age-specific blood pressures in five cities: a study of Indian women. NKP Salve Institute of Medical Sciences, Nagpur, India. Int J Cardiol. 1998 Jan 31;63(2):165-73.

43. Harrison TA, Hindorff LA, Kim H, Wines RC, Bowen DJ, McGrath BB, Edwards KL (2003): Family history of diabetes as a potential public health tool. Am J Prev Med.24:152-9.

44. Annis AM, Caulder MS, Cook ML, Duquette D (2005): Family history, diabetes, and other demographic and risk factors among participants of the National Health and Nutrition Examination Survey 1999-2002. Prev Chronic Dis. 2:A19.

45. Hariri S, Yoon PW, Qureshi N, Valdez R, Scheuner MT, Khoury MJ (2006): Family history of type 2 diabetes: a population-based screening tool for prevention? Genet Med 8:102-108.

46. OpenUrlBarlassina C, Lanzani C, Manunta P, Bianchi G (2002): Genetics of essential hypertension: from families to genes. J Am SocNephrol: JASN. 13 Suppl 3:S155-64.View ArticlePubMedGoogle Scholar

47. Carretero OA andOparil S (2000): Essential hypertension. Part I: definition and etiology. Circulation. 101(3):329-35.

48. Priyanga Ranasinghe,

Dilini N. Cooray,Ranil Jayawardena

Prasad Katulanda (2015):The influence of family history of Hypertension on disease prevalence and associated metabolic risk factors among Sri Lankan adults. BMC Public Health. 15:576.

49. Duclos M, Oppert JM, Verges B, et al.(2013): SFD Diabetes and Physical Activity Working Group Physical activity and type 2 diabetes. Recommendations of the SFD Francophone Diabetes Society diabetes and physical activity working group.Diabetes Metab.39(3):205-16.

50. Cornelissen VA and Smart NA (2013): Exercise training for blood pressure: a systematic review and metaanalysis. J Am Heart Assoc. 2(1):e004473. [PMC free article] [PubMed]

51. Leitzmann MF, Park Y, Blair A, et al. (2007): Physical activity recommendations and decreased risk of mortality. Arch Intern Med. 2167(22):2453-2460.

52. Eriksson KF and LindgardeF (1991):Prevention of Type 2 (non-insulindependent) diabetes mellitus by diet and physical exercise; 6-year feasibility study. Diabetologia.34(12):891-898.

53. Cheung BM, Ong KL, Cherny SS, Sham PC et al. (2009): Diabetes prevalence and therapeutic target achievement in the United States, 1999to 2006. Am J Med.; 122: 443- 453.

54. Donald CS (1988): Etiology and Prevalence of Hypertension in Diabetic Patients. Diabetes Care.11(10):821-827.

55. Kannel WB (2000): Fifty years of Framingham study contributions to understanding hypertension. J Hum Hypertens.14:83-90. [PubMed]

56. Qun Yan, Dongmei Sun, Xu Li1, Guoliang Chen, Qinghu Zheng, Lun Li, Chenhong Gu and Bo Feng (2016): Association of blood glucose level and hypertension in Elderly Chinese Subjects: a community based study. BMC Endocrine Disorders.16:40.

57. Heianza Y, Arase Y, Kodama S, Hsieh SD, Tsuji H, Saito K, et al. (2015): Fasting glucose and $\mathrm{HbA} 1 \mathrm{C}$ levels as risk factors for the development of hypertension in Japanese individuals: Toranomon hospital heath management center study 16(TOPICS 16). J Hum Hypertens. 29:254-9. 
58. Stratton IM, Kohner EM, Aldington SJ, Turner RC, Holman RR, Manley SE, Matthews DR (2001): UKPDS 50: risk factors for incidence and progression of retinopathy in Type II diabetes over 6 years from diagnosis. Diabetologia. 44:156-163. [PubMed]

59. O'Donnell VB (2003): Free radicals and lipid signaling in endothelial cells. Antiox Redox Signal. 5:195-203. [PubMed]
60. Borghi C (2002): Interactions between hypercholesterolemia and hypertension: Implications for therapy. CurrOpinNephrolHypertens. 11:489-96. [PubMed]

61. Fagan TC and Sowers J (1999): Type 2 diabetes mellitus: Greater cardiovascular risks and greater benefits of therapy. Arch Intern Med. 159:1033-4. 
Table 1: Socio-demographic and life style factors among the hypertensive and nonhypertensive diabetic patients

\begin{tabular}{|c|c|c|c|c|}
\hline Risk factors & $\begin{array}{c}\text { DM with HPN } \\
203(\%)\end{array}$ & $\begin{array}{c}\text { DM without HPN } \\
97(\%)\end{array}$ & $\chi^{2}$ & $\mathbf{P}$ \\
\hline $\begin{array}{l}\text { Sex } \\
\text { Male } \\
\text { Female }\end{array}$ & $\begin{array}{r}86(42.4) \\
117(57.6)\end{array}$ & $\begin{array}{l}27(27.8) \\
70(72.2)\end{array}$ & 5.90 & $0.02 *$ \\
\hline $\begin{array}{l}\text { Social class } \\
\text { Low } \\
\text { Moderate }\end{array}$ & $\begin{array}{r}176(86.7) \\
27(13.3)\end{array}$ & $\begin{array}{l}72(74.2) \\
25(25.8)\end{array}$ & 7.12 & $0.01 *$ \\
\hline $\begin{array}{l}\text { Family history of DM } \\
\text { Yes } \\
\text { No }\end{array}$ & $\begin{array}{r}132(65.0) \\
71(35.0)\end{array}$ & $\begin{array}{l}46(47.4) \\
51(52.6)\end{array}$ & 8.42 & $0.004 *$ \\
\hline $\begin{array}{l}\text { Physical exercise } \\
\text { Yes } \\
\text { No }\end{array}$ & $\begin{array}{r}6(3.0) \\
197(97.0)\end{array}$ & $\begin{array}{l}27(27.8) \\
70(72.2)\end{array}$ & 41.5 & $<0.001 *$ \\
\hline $\begin{array}{l}\text { Follow diabetic diet } \\
\text { Yes } \\
\text { No }\end{array}$ & $\begin{array}{r}21(10.3) \\
182(89.7)\end{array}$ & $\begin{array}{l}20(20.6) \\
77(79.4)\end{array}$ & 5.87 & $0.01 *$ \\
\hline Age (Mean \pm SD) & $56.58 \pm 6.74$ & $52.02 \pm 7.69$ & $4.99^{\#}$ & $0.003 *$ \\
\hline
\end{tabular}

\#t-test; *Significant

Table 2: Physical and biochemical profilesof the hypertensive and non-hypertensive diabetic patients

\begin{tabular}{|c|c|c|c|c|}
\hline $\begin{array}{c}\text { Physical and biochemical } \\
\text { variables }\end{array}$ & $\begin{array}{c}\text { DM with HPN } \\
\text { N=203 } \\
\mathbf{N}(\%)\end{array}$ & $\begin{array}{c}\text { DM without HPN } \\
\mathbf{N}=97 \\
\mathbf{N}(\%)\end{array}$ & $\chi^{2}$ & $\mathbf{P}$ \\
\hline $\begin{array}{l}\text { Systolic Blood Pressure SBP } \\
\text { Normal }<135 \mathrm{~mm} . \mathrm{Hg} \\
\text { High } \geq 135 \mathrm{~mm} . \mathrm{Hg}\end{array}$ & $\begin{array}{r}91(44.8) \\
112(55.2)\end{array}$ & $\begin{array}{l}86(88.7) \\
11(11.3)\end{array}$ & 52.1 & $<0.001^{*}$ \\
\hline $\begin{array}{l}\text { Diastolic Blood Pressure DBP } \\
\text { Normal }<85 \mathrm{~mm} . \mathrm{Hg} \\
\text { High } \geq 85 \mathrm{~mm} . \mathrm{Hg}\end{array}$ & $\begin{array}{r}33(16.3) \\
170(83.7)\end{array}$ & $\begin{array}{l}67(69.1) \\
30(30.9)\end{array}$ & 82.4 & $<0.001 *$ \\
\hline $\begin{array}{l}\text { BMI } \\
\text { Normal } \\
\text { Overweight } \\
\text { Obese }\end{array}$ & $\begin{array}{r}14(6.9) \\
34(16.7) \\
155(76.4)\end{array}$ & $\begin{array}{l}17(17.6) \\
24(24.7) \\
56(57.7)\end{array}$ & 11.9 & $<0.001 *$ \\
\hline $\begin{array}{l}\text { Total cholesterol } \\
\text { Desirable } \\
\text { Borderline high \& High }\end{array}$ & $\begin{array}{r}77(37.9) \\
126(62.1)\end{array}$ & $\begin{array}{l}51(52.6) \\
46(47.4)\end{array}$ & 5.75 & $0.02 *$ \\
\hline $\begin{array}{l}\text { Triglycerides } \\
\text { Desirable } \\
\text { Borderline high \& High } \\
\end{array}$ & $\begin{array}{r}115(56.7) \\
88(43.3) \\
\end{array}$ & $\begin{array}{l}44(45.4) \\
53(54.6)\end{array}$ & 3.35 & 0.07 \\
\hline $\begin{array}{l}\text { Fasting Blood Sugar FBS } \\
\text { Normal } \\
\text { High }\end{array}$ & $\begin{array}{r}41(20.2) \\
162(79.8)\end{array}$ & $\begin{array}{l}32(33.0) \\
65(67.0)\end{array}$ & 5.83 & $0.01 *$ \\
\hline
\end{tabular}

*Significant 
Table 3: Incidence of complications among the hypertensive and non-hypertensive diabetic patients

\begin{tabular}{|l|r|r|r|r|}
\hline \multicolumn{1}{|c|}{ DM complications } & $\begin{array}{c}\text { DM with HPN } \\
\mathbf{N = 2 0 3} \\
\mathbf{N}(\mathbf{\%})\end{array}$ & $\begin{array}{c}\text { DM without HPN } \\
\mathbf{N = 9 7} \\
\mathbf{N}(\boldsymbol{\%})\end{array}$ & \multicolumn{1}{c|}{$\chi^{\mathbf{2}}$} & \multicolumn{1}{|c|}{$\mathbf{P}$} \\
\hline Hypoglycemic coma & $37(18.2)$ & $12(12.4)$ & 1.647 & 0.199 \\
\hline FBS >300 mm/dl & $58(28.6)$ & $15(15.5)$ & 6.125 & $0.013^{*}$ \\
\hline Neuropathy & $152(74.9)$ & $68(70.1)$ & 0.765 & 0.382 \\
\hline Eye problems & $73(36.0)$ & $23(23.7)$ & 4.526 & $0.033^{*}$ \\
\hline CVD & $82(40.4)$ & $18(18.6)$ & 14.085 & $<0.001^{*}$ \\
\hline Renal diseases & $10(4.9)$ & $2(2.1)$ & 1.402 & 0.237 \\
\hline Diabetic foot & $2(0.98)$ & $3(3.1)$ & 1.779 & 0.182 \\
\hline Infections & $92(45.3)$ & $36(37.1)$ & 1.807 & 0.179 \\
\hline
\end{tabular}

*Significant

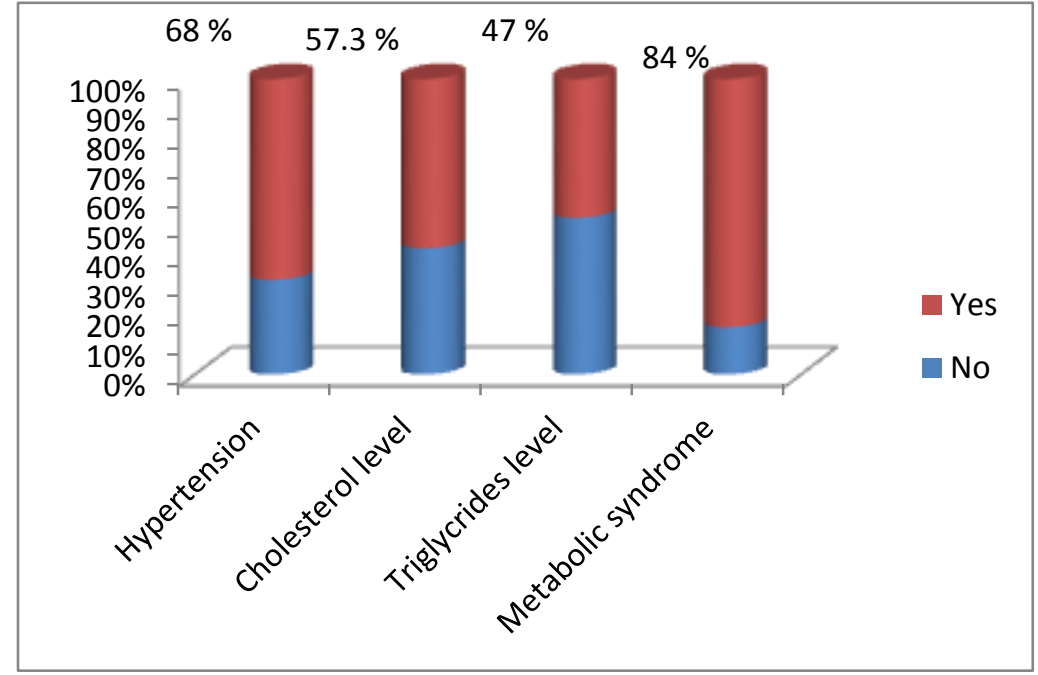

Figure 1: Prevalence of hypertension, dyslipidemia and metabolic syndrome among the studied diabetic patients 